\title{
Study of Corporate Elements Culture in Effective Secondary Schools
}

\author{
Hossein Zainalipour $^{1 *}$, Fatemeh Mahmoodi ${ }^{2}$, Yaghoob Raissi Ahvan ${ }^{3}$ \\ 1.Assistant Professor, Faculty of Humanities, University of Hormozgan, Bandar Abbas, Iran. \\ 2.Ph.D. Student of Educational Administration, Islamic Azad University, Marvdasht Branch, Marvdasht, Iran. \\ 3.Ph.D. Student of Curriculum, Faculty of Humanities, University of Hormozgan, Bandar Abbas, Iran. \\ *Corresponding author: hzainalipour@yahoo.com
}

\begin{abstract}
The present research aimed to identify the elements of corporate culture in Farzanegan schools (schools for gifted and talented students) of Bandar Abbas in Iran. National Organization for Development of Exceptional Talents ( NODET ) are national selective schools in Iran developed specifically for the development of exceptionally talented students. In this study we employ a grounded theory approach and a systematic plan. The population of this study consists of all principals, teachers, and students of high schools for gifted students in the city of Bandar Abbas in Iran. Fifty-two principals, teachers, and students were selected through purposeful and theoretical sampling and were interviewed by a main question and a number of open questions. The reliability of research for data collection tools was determined by using generator questions. The data were analyzed using grounded theory. In the conceptualization stage, 33 concepts were extracted from the responses of the interviewees. The concepts were categorized in three dimensions of corporate culture and then the known dimensions were free coded with titles of organized organization, role model, and strategic initiatives. Then, code of strategic initiatives (actions) was selected as the key code and explained the other codes by paradigm pattern.
\end{abstract}

Keywords: effective schools, elements of corporate culture, grounded theory, qualitative research.

\section{Introduction}

The most fundamental characteristic of successful organizations in the 21 st century is their emphasis on culture (Peter \& Waterman, 1982). Culture is a powerful tool that can change the world (Peter and Robert, 2004).In management, corporate culture attitude has influenced educational organizations as social systems as much as it has influenced trade organizations. Educational places that make up the base of organizations have a culture of their own. Corporate culture is so important that researchers of educational management have conducted many studies in this field in recent years. Since in educational organizations human relations are important, the concept of organizational culture becomes more important. The principal of a school can make his/ her school outstanding with a good corporate culture. As school leaders, principals can influence and mold school culture in positive ways. The principals who are able to work with teachers, students and community members to create a commitment to common values and a bond between one another and the schools can create educational culture successfully.

In this way, specific corporate culture of school can preserve its authenticity (Denison, 1990). No two schools or principals are alike. The studies show that despite many differences, principals who understand the culture of their institutions can be successful at achieving reforms and preserving their authenticity. In educational organizations, administration should benefit from the experience, talent, intellectual ability of human resources, especially principals and teachers, which is achievable by establishing a rich corporate culture that balances and coordinates the demands, needs and expectations of knowledge, abilities and skills (Denison, 1990). Culture can distinguish communities from each other and mark the existence of a particular society. In other words, the identity of a community or organization depends on its culture. No doubt, culture is 
the highest element that determines the existence of a society (Castells, 2011). Eliot (2010) defines culture as a set of values, norms, patterns, beliefs, customs, and commitments that guide the behavior of individuals in a society. Based on this, corporate culture refers to the norms, values and beliefs that determine the behavior and performance of staff. Corporate culture can either weaken or strengthen employees, and can either provide opportunities for success or failure. Corporate culture is a system of common perceptions that members of an organization hold. Argyris (1993) believes that corporate culture is an alive system that is manifested in the manner that people reveal themselves, and the way they think, feel, and interact. Almost all researchers define corporate culture as a set of values, beliefs, opinions, assumptions and common norms that govern an organization. An effective school is one of these organizations which has its own educational and corporate culture. As the concept of corporate culture of an effective school implies, this type of organization or school should be a model for other schools. What occurs in educational institutions should be interpreted in its specific field of culture. Thus, by identifying the elements of educational and corporate culture, the ground can be paved for growth and development of students. The principals and even the parents can be involved in students' making progress. Like most concepts of human and social sciences, there is no clear and comprehensive definition for school culture. The definitions used in the research literature are influenced by the general definition of the term culture. According to David and Fahey (2000) school culture is a linking factor which teachers, parents, and administrators require to coordinate practices and local (regional)tradition. Local culture is reflected in various forms in school culture. School culture is a set of values, beliefs, norms, rituals, beliefs, and priorities that guides the behavior and actions of employees. School culture refers to the beliefs and values within the school that guide behaviors and actions of teachers, educators, students, and parents in the school. Deal and Peterson (1999) defined school cultures as a collection of "traditions and rituals that have been built up over time as teachers, students, parents, and administrators work together and deal with crises and accomplishments" (p. 4).

These values, beliefs, and norms guide the behavior and actions of people. Values are the mainstay of managers in decision-making. The study of effective schools' organizational culture is important, because the progress of schools requires emphasizing these elements and implementing them in school and outside of school. Since schools have their own cultural elements, in order to achieve a more effective education system, the cultural elements that should be dominant in school should be determined (Firestone \& Wilson, 1985). According to Van den Hooff and Huysman (2009) school is a social group made up of individuals whose experiences, culture, and personalities are different. The interaction between members of a school is largely influenced by the school atmosphere. Prior to being an educational organization, school is a small community. The common ground between organization and society is the existence of social action in both, but what distinguishes them is the importance given to the procedures. The atmosphere of social interaction at the school level can be considered as school culture (Deal \& Peterson, 2016) . There are many factors contributing to cultural elements of effective schools. School culture is influenced by all elements within it. The success of a school depends not only on the location and characteristics of the school, its history, its founders, teachers, administrators, students, and honors of the school, but also on the specific cultural elements of the school. Organizational culture of schools, in general, and cultural elements of effective schools, in 
particular, became important when some specialists, including Ivan Ilyich (Deal \& Peterson, 2016) criticized the current performance of schools. In the meantime, the identification and definition of school effectiveness is extremely complex and potentially controversial. However, identifying characteristics and organizational atmosphere and culture of some schools makes cultural elements of effective schools clear. The effective school plays a vital role in collecting academic information and combining theories and experiences about the good performance of schools in today's world. Rudasill, Snyder, Levinson, and Adelson (2017) have defined school effectiveness as; the result of all theories and research studies about the means-ends relationships between educational processes and outcomes, in particular student knowledge and skills... aiming at explanations for differences in student achievement between schools and classrooms". According to Scott (2017) effective schools are a kind of organization and therefore have their own cultural elements. Identifying the cultural elements of effective schools that have a record of success in their academic experiences can help other schools to benefit from their experience and improve the level and quality of education of students.

Several studies have been conducted on the elements of educational and corporate culture in Farzanegan schools (schools for gifted and talented students) in Iran. Nevertheless, none of them has specifically studied cultural elements of effective schools.

Amerifar and Jahani (2013) examined the relationship between organizational culture and effectiveness of schools from the perspectives of principals and high school teachers in Shiraz. In Amerifar and Jahani (2013) study, the researchers sought to examine the relationship between organizational culture and improving the quality of secondary schools. The results showed that teamwork, attention to the needs of clients, providing the components of empowerment and delegation of staff, providing the conditions for change in school, effective leadership, attention to long-term and short time goals in school are considered the components of corporate culture. The analysis of the data showed that there is significant positive correlation between organizational culture and quality improvement of high schools in Bandar Abass. Similarly, there is significant positive correlation between the components of organizational culture on the one hand and delegating the staff, developing teachers and staff's capabilities, paying attention to core values, creating harmony and unity among employees, providing the conditions for a change in the school, effective leadership, and long-term and short-term goals on the other hand.

\section{Material and Methods}

This study lies in qualitative grounded theory research category. In grounded theory research, the researcher does not seek to generalize the results to other communities. An especial characteristic of this methodology is the requirement that there should be a high degree of access within the organizations under scrutiny, which permits the researchers to be close to the phenomenon under study. A key tenet of this approach is that the insights should be driven by the data and not by one or more hypotheses (Moran et al., 2016). As Charmaz and Henwood (2017) note "Grounded theory gives priority to the studied phenomenon or process rather than the setting itself". This rationale applied to this specific method chosen. A recursive process, grounded theory compares data from the beginning of the research project and continuously analyzes it throughout, rather than waiting until all data are collected, to identify emerging relationships which "grounds" new theoretical interpretations within the data collected and analyzed (Charmaz \& Henwood, 2017). 
Studies that incorporate grounded theory approach are basically a step towards conceptual thinking and theory building rather than empirical testing of the theory. Hence, a qualitative research approach is used in these types of studies. Particularly it is conceptual thinking and approach. He just tries to uncover, identify, and describe phenomena, factors, and features. Theory building usually is going to conduct an inductive, constructivist 'Grounded Theory' to carry out this research with qualitative approach, grounded theory has been used because the recognition of cultural elements requires exploration and discovery, and this is possible with grounded theory methodology. Grounded theory is a qualitative systematic procedure to produce theories that describe an action or interaction process on a real split case in the general sense.

In this method, data collection, analysis and theories are interconnected with each other. Grounded theory is a deductive theory based on probe methods, detection, and classification of factors and properties of an abstract concept (Feibert, 2017). In this the use of open coding, axial coding, and selective coding of data is emphasized (Knigge, 2017). In open coding, the collected data about a cultural issue are encoded into concepts and then into categories. In axial coding, one of the concepts is considered the axe of category. In selective coding, categories and themes are attributed to the main concept and categories are refined. Method, research is based on concepts, categories, and theories.

The population of this study consists of all principals, teachers, and students of high schools for gifted students in the city of Bandar Abbas in Iran. Our data were collected with the use of individual face-to-face interviews. In grounded theory, theoretical sampling is used and the decision about selecting the sample is organized during the research process. In this method, sampling is not similar to quantitative research. In other words, the range of population is not pre-defined and its characteristics are not known. The starting point grounded theory is very important because it is the first step in achieving researcher's theory. One of the basic assumptions of grounded theory is that the data from the past should not affect theories of research and data collection. In addition, the initial phase of the study based on grounded theory has an exploratory nature. Therefore, in this study, we attempted to use a group of individuals in the starting point that could accelerate collecting data related to the theory. For sampling, the purposive sampling and snowball sampling were used as the aim was reaching a saturation point of responses to cultural elements. To this end, first 4 principals were chosen by random sampling from gifted schools' principals. For each principal 4 teachers and for each teacher 2 students were chosen randomly from gifted schools as the sample of the study (total of 52). However, the answer reached the saturation point by 28 individuals. In this study, a main open-ended question about the elements of effective organizational culture of schools was used for interview. In order to increase the reliability of data collection tools, essay questions were used; such as "how is the balance between academic activities and entertainment and sports for students?", "how is the implementation of artistic and cultural activities in school?". In addition to the above questions, the researcher used observations and technical notes to gather data by attending at classes and watching the activities.

Data analysis was done using a systematic plan of grounded theory method. In this study, a systematic design has been used for the application of grounded theory research method. In this design, the use of open coding, axial coding, and selective coding of data is emphasized (Knigge, 2017). In open coding, the collected data about a cultural issue are encoded into concepts and 
then into categories. In axial coding, one of the concepts is considered the axe of category. In selective coding, categories and themes are attributed to the main concept and categories are refined. The analysis is done in five stages: natural coding, conceptualization, open coding, axial coding, and selective coding. Of course, natural coding and extraction of concepts are two prerequisite stages for grounded theory analysis. In grounded theory, open coding, axial coding, and selective coding are known as theoretical coding. The first stage of data analysis based on grounded theory method is done using theoretical coding. Theoretical coding is a method for analyzing the data collected in order to develop a theory in grounded theory.

Identifying natural codes is the first stage. At this stage, data gathered through observation, answers to interview questions, and researcher's notes are entered first-handedly. In grounded theory, this first-hand information is called natural codes (Knigge, 2017). At this point, all responses, / statements of each of the principals, teachers, and students (the sample)) were coded separately by researchers. Using MAXQDA software, the codes were separated and the themes formed.

Conceptualization is the second stage: The first step in creating categories out of raw data / natural codes is identification and extraction of the main concepts in sentences. Researchers create categories by identifying the relationship between the concepts contained in statements. Therefore, prior to categorizing, researcher should identify the concepts for those categories. In other words, concepts (understandable sentences) are a prerequisite for building categories. Analysis at this stage is focused on what concepts can be deduced from the data collected (natural codes).

At this point, the codes of all accepted sentences were put in concept extraction table. In other words, all coded sentences were converted to concepts and therefore the codes of some inappropriate statements were not included in the table of extracted concepts (original categorization). At this stage, the concepts were named based on the characteristics of the sentences, but the severity and direction of the statements were not determined in concepts (it was done in axial coding stage). It should be noted that the concentration of responses was on the first individuals (principals, teachers, and students) as most responses of next individuals were repeated and the code had not been inserted. Even in some cases, because of saturation of responses, there was no need to interview more than 12 students and teachers. Therefore, the concentration of codes on the first individuals does not mean their responses are privileged. At this stage, 33 concepts were extracted for open coding.

The third stage is open coding. In this stage, researcher creates sub-categories through detailed configuration of information. Open coding is based on the features of information, concepts, and dimensions of each feature (range). In other words, naming a concept based on the characteristics (type of relationship) of concepts and information is called open coding. Analysis at this stage is focused on the kind of relationship perceived between concepts. In this study, the emphasis, frequency, and functionality of an issue have been used for the collected data to be open coded and categories were created at this stage. So that the major goal at this stage was creating the sub-categories of the elements of corporate culture. For creating sub categories and open coding, two basic actions were done: The first step was forming the framework of categories (dimensions) of corporate culture. The dimensions considered for the elements of corporate culture in effective schools were based on previous research and definitions in this area. In 
subsequent stages(after the separation and the formation of concepts by software), no concept was found for some dimensions. As a result, the category was removed. In some cases, the concepts of two or three codes were combined and in some other cases, there were new code having no position in any of the categories (dimensions) had no position. Later, we defined a dimension for them.

Sub categories or dimensions were created through categorizing the concepts based on their similarities and differences. However, the names had not been specified in this stage yet in order to cover all the concepts and clearly define subcategories based on them. Sub categories of the elements of corporate culture of effective schools were obtained in three dimensions: organization, myth, and procedures. The second action was naming each of the sub-categories/ dimensions based on the response characteristics and the relationship between the concepts of each category. Thus, for each of the sub-categories/dimensions, a name was determined as follows: the issue of organization (organized), mythology (being role models), and procedures (the strategies).

The fourth stage: axial coding: In this stage, the researcher selects one of the open codes as the axis and links other open codes to it. Axial coding is explained by several factors. Here, the paradigm of Corbin and Strauss (2008) has been used. The paradigm pattern has 6 indicators (code-oriented, causal relationship, underlying conditions, mediated conditions, strategies, and outcomes), which have been implemented in this study. Analysis at this stage focuses on the conditions and the kind of strategy that make a special connection between the concepts. In the present study, axial coding was based on four criteria above done by researchers.

The fifth stage: selective coding: it is based on narrative explanation and the basic criterion of its selection is the process of occurring phenomena. In this study, by process we mean corporate culture in effective schools. Thus, in coding, especially in selective coding, two factors of distinguishing / differentiation and extension are considered. This is because classification of methods and their factors is achieved by distinguishing and extension. Analysis at this stage is focused on the outcome (process) obtained by the relationship between axial codes and factors causing them.

\section{Results}

The extraction of concepts: The concepts obtained by natural codes (accepted sentences) related to the elements of corporate culture through combining and removing some of the codes are shown in Table 1. In other words, all statements of the statistical sample have received codes, but some codes were removed and excluded (due to being repetitive, meaningless, and irrelevant). Finally, 33 concepts were obtained by the statements of principals, teachers, and students.

Open coding stage: At this stage, three dimensions have been considered for the elements (organization, myth and procedures). These three categories were coded based on the characteristics of the interview statements with respect to the categories of organized structure, behavioral pattern of school, and strategic actions. 
Table 1. The extracted concepts before sub-categorization the concepts obtained by natural codes/interview

The popularity of authorities(8M1), Pilgrimage camps(9M1), recreational camp (10M1), scientific camp (10M1), healthcare students (8M3), holding conferences (9M3), Association of Parents (10M3), praising good teacher (13M3), holding religious rituals monthly (7M7).

Choosing a class representative (8 T2), lesson plan meetings (5T3), a model scholar (8T3), taking all students to science camp without any specific conditions (7T4), Good morals of principal (10T4), counseling and family workshops at school (7T9), inviting great speakers (11T6).

Student Council (3S3), model and attractive teachers (5S3), inviting professors and top consultants (8S3), weekly praying(9S3), holding festivals and competitions about the Qur'an (5S4), Muharram rituals ( 7S4), inviting parents in religious ceremonies $(8 \mathrm{~S} 8)$.

Table 2. The extracted concepts after sub-categorization

\begin{tabular}{|l|l|}
\hline Dimensions & the concepts obtained by natural codes/interview \\
\hline $\begin{array}{l}\text { Organized } \\
\text { structure }\end{array}$ & $\begin{array}{l}\text { Healthcare students (8M3) - Student Council (3S3) - lesson plan meetings (5T3) - choosing a class } \\
\text { representative (8T2) - parents association (10M3) }\end{array}$ \\
\hline Myth & $\begin{array}{l}\text { Modeling top student (8T3) - praising good teacher (13M3) - popularity of authorities (8M1) - } \\
\text { attractive teachers (3S5) - morality of principal (10T4) }\end{array}$ \\
\hline Procedures & $\begin{array}{l}\text { Pilgrimage camps(9M1), recreational camp (10M1), scientific camp (10M1), ), taking all students } \\
\text { to science camp without any specific conditions (7T4), holding conferences (9M3), counseling and } \\
\text { family workshops at school (7T9), inviting great speakers (11T6) weekly praying(9S3), holding } \\
\text { festivals and competitions about the Qur'an (5S4), Muharram rituals ( 7S4), inviting parents in } \\
\text { religious ceremonies (8S8). }\end{array}$ \\
\hline
\end{tabular}

Selective coding stage: The third and final stage of coding is selective coding, which continues axial coding at a more abstract level. In fact, at this stage, based on the data, researcher reaches a hypothesis. One of the most difficult stages of conducting research based on grounded theory is determining the time1998to finish it. Flick (2014) believes it is researchers who should decide about the finishing time (sampling and coding). According to Rennie (1998), after creating some high -level categories, researcher needs to recognize the key concept that organizes the theory. This key concept which is a top-level category is called central category by Glaser. At this stage, the main responsibility of researcher is determining the conceptual connection that links all higher level categories to each other. Thus, at this stage, the relationship between the subcategories (Open coding), the central category, and what is in the paradigm pattern is explained in a narrative way. Based on this, strategic actions are selected as central category in the elements of corporate culture. In terms of educational and scientific systems, effective schools have more facilities. Therefore, the community and education organization have higher expectations from effective schools. In this regard, the school also provides background conditions (underlying conditions) to manage the school effectively and pursue the activities with targeted programs (strategy). As mentioned before, the expectations of parents and society from these schools exacerbate the purposefulness of these schools (mediated conditions). The result is that these schools gain a higher position and become model schools. Therefore, the 
cultural elements of effective high schools for girls in the city of Bandar Abbas are: achieving a top educational status, and being a role model for other schools.

\section{Discussion and Conclusion}

Using grounded theory, this study was conducted in order to identify cultural elements of effective schools in Bandar Abbas. The results were obtained by interviewing 52 individuals as sample. The findings obtained by examining the interviews suggest that effective schools have benefitted from strategic actions for the management of their educational system and success. In this study, through adoption of a proper scientific process, it was attempted to reach a general agreement on the elements of effective schools in order to use them as a model for other schools. In this study, the categories were extracted by investigating the interviews and the interpretation of data and coding. Finally, it was found out that one category is the most clearly in the data and concepts. This category which was selected as central category is strategic actions. The reason for choosing this title is that all concepts and categories somehow referred to it. For example, concepts like recreational camp, scientific camp, taking all students to science camp without any specific conditions, holding conferences, counseling and family workshops at school, inviting great speakers, weekly praying, holding festivals and competitions about the Qur'an, Muharram rituals, inviting parents in religious ceremonies, healthcare students, Student Council, lesson plan meetings, and choosing a class representative all need targeted and operational planning and implementing them requires strategic actions. Although operating activities as cultural elements of effective schools directly do not specify the conditions for successful academic performance of students, they provide the necessary conditions for it.

\section{References}

Amerifar, F., \& Jahani, J. (2013). The relationship between organizational culture and effectiveness of school from the perspective of administrators and teachers in secondary schools in Shiraz. Journal of Public Administration, University of Shiraz, 12, 23-36.

Argyris, C. (1993). Knowledge for action: A guide to overcoming barriers to organizational change: ERIC.

Castells, M. (2011). The rise of the network society: The information age: Economy, society, and culture (Vol. 1): John Wiley \& Sons.

Charmaz, K., \& Henwood, K. (2017). Grounded Theory Methods for Qualitative Psychology. The SAGE Handbook of Qualitative Research in Psychology, 238.

Corbin, J., \& Strauss, A. (2008). Basics of qualitative research: Techniques and procedures for developing grounded theory. Thousand Oaks.

David, W., \& Fahey, L. (2000). Diagnosing cultural barriers to knowledge management. The Academy of management executive, 14(4), 113-127.

Deal, T. E., \& Peterson, K. D. (1999). Shaping school culture: The heart of leadership: ERIC.

Deal, T. E., \& Peterson, K. D. (2016). Shaping school culture: John Wiley \& Sons.

Denison, D. R. (1990). Corporate culture and organizational effectiveness: John Wiley \& Sons.

Eliot, T. S. (2010). Notes towards the Definition of Culture: Faber \& Faber.

Feibert, D. C. (2017). Improving healthcare logistics processes. DTU Management Engineering. 
Firestone, W. A., \& Wilson, B. L. (1985). Using bureaucratic and cultural linkages to improve instruction: The principal's contribution. Educational Administration Quarterly, 21(2), 7-30.

Flick, U. (2014). An introduction to qualitative research: Sage.

Knigge, L. G. (2017). Grounded Theory. The International Encyclopedia of Geography.

Moran, C., Tapp, R. J., Hughes, A. D., Magnussen, C. G., Blizzard, L., Phan, T. G., . . . Münch, G. (2016). The association of Type 2 Diabetes Mellitus with cerebral gray matter volume is independent of retinal vascular architecture and retinopathy. Journal of diabetes research, 2016.

Peter, T. J., \& Waterman, R. H. (1982). In search of excellence: Lessons from America's bestrun companies. Warner Book, New York.

Rennie, D. L. (1998). Grounded theory methodology: The pressing need for a coherent logic of justification. Theory \& Psychology, 8(1), 101-119.

Rudasill, K. M., Snyder, K. E., Levinson, H., \& Adelson, J. L. (2017). Systems View of School Climate: a Theoretical Framework for Research. Educational psychology review, 1-26.

Scott, T. M. (2017). Training Classroom Management With Preservice Special Education Teachers: Special Education Challenges in a General Education World. Teacher Education and Special Education, 40(2), 97-101.

Van den Hooff, B., \& Huysman, M. (2009). Managing knowledge sharing: Emergent and engineering approaches. Information \& management, 46(1), 1-8. 